\title{
Antioxidant Activity of Ethanolic Extract and Various Fractions from Green Tea (Camellia sinensis L.) Leaves
}

\author{
Karmika Indarti ${ }^{1}$, Elsa Fitria Apriani ${ }^{2}$, Agung Eru Wibowo ${ }^{3}$, Partomuan Simanjuntak ${ }^{1, *}$
}

\section{Karmika Indarti', Elsa Fitria Apriani ${ }^{2}$, Agung Eru Wibowo ${ }^{3}$, Partomuan Simanjuntak ${ }^{1, *}$}

${ }^{1}$ Magister of Pharmaceutical Sciences, Faculty of Pharmacy, Pancasila University, Jakarta, INDONESIA.

${ }^{2}$ Department of Pharmacy, Faculty of Mathematics and Natural Sciences, Sriwijaya University, South Sumatra, INDONESIA.

${ }^{3}$ Center for Pharmaceutical and Medical Technology, Agency for the Assessmenet and Application of Technology (BPPT) Puspiptek Serpong, INDONESIA.

\section{Correspondence}

Partomuan Simanjuntak

Magister of Pharmaceutical Sciences, Faculty of Pharmacy, Pancasila University, Jakarta, INDONESIA

E-mail: partomuansimanjtk@yahoo.com

History

- Submission Date: 22-03-2019;

- Review completed: 12-04-2019;

- Accepted Date: 06-05-2019.

DOI : 10.5530/pj.2019.11.122

Article Available online

http://www.phcogj.com/v11/i4

\section{Copyright}

(c) 2019 Phcogi.Com. This is an openaccess article distributed under the terms of the Creative Commons Attribution 4.0 International license.

\begin{abstract}
Background: Free radicals are one of the causes that can cause premature aging and degenerative disease. To overcome this problem, the body needs antioxidant intake. Green tea (Camellia sinensis L.) leaves are one of the plants known as antioxidant agent due to its flavonoids and phenolic compounds or better known as catechin compounds. Catechin is polar flavonoid compounds so it is necessary to separate it from non-polar compounds so their antioxidant activity becomes effective. Objective: This study aims to determine antioxidant activity of ethanolic extract of green tea leaves and its fractions namely ethyl acetate and water fraction, and measure the total flavonoid content, total phenolic content and catechin content. Materials and Methods: Green tea leaves extracted using maceration method with $96 \%$ ethanol. Fractionation was conducted using liquid-liquid extraction using a solvent of $n$-hexane, ethyl acetate and water. Screening of flavonoid and phenolic and antioxidant activity was performed against the ethanolic extract, ethyl acetate fraction and water fraction. Antioxidant activity was determined by 2,2-diphenyl-1-picrylhydrazyl method using ultravioletvisible spectrophotometry with ascorbic acid as standard. Results: The ethanolic extract, ethyl acetate fraction and water fraction contains flavonoids and phenolic compounds. The $I_{50}$ value of ethanolic extract, ethyl acetate fraction and water fraction were $9.017 ; 3.926$ and $7.408 \mu \mathrm{g} / \mathrm{mL}$ consecutively. The ethyl acetate fraction also showed better antioxidant activity than ascorbic acid $(4.855 \mu \mathrm{g} / \mathrm{mL})$. Conclusion: The ethanolic extract, ethyl acetate fraction and water fraction showed very powerful antioxidant activity but ethyl acetate fraction has the best antioxidant activity.
\end{abstract}

Keywords: Antioxidant activity, DPPH method, Ethanolic extract, Ethyl acetate fraction, Green tea leaves.

\section{INTRODUCTION}

Free radicals, known as reactive oxygen species (ROS), are the products of normal cellular metabolism. A free radical can be defined as an atom or molecule containing one or more unpaired electrons. The odd number of electron(s) of a free radical makes it unstable, short lived and highly reactive. $^{1-3}$ Free radicals are compounds that trigger the aging process and degenerative diseases. Antioxidants are compounds that prevent the formation of free radicals. Antioxidants are divided into two types, natural and synthetic antioxidant. Natural antioxidant commonly found in plants such as fruits, grains, and vegetables. Some natural antioxidant compounds are derivatives of flavonoids, phenol, ascorbic acid, coumarin, hydroxycinnamic, dihydroflavone, tocopherol, and catechin. Synthetic antioxidants include butyl hydroxylanisol, butyl hidroxytoluen, propyl gallate, ethoxyquin. ${ }^{4}$ Synthetic antioxidants such as butylated hydroxy aniline (BHA) and butylated hydroxy toluene (BHT) have been known to have large side effects including causing liver damage. ${ }^{5}$ This encourages the development of natural product to be a source of antioxidants.
Natural product that can be used as antioxidants is green tea leaves (Camellia sinensis L). The antioxidant activity of green tea is caused by polyphenolic compounds, especially flavonoid groups. ${ }^{6,7}$ Catechin is flavonoids compound that contained in green tea leaves. The types of catechins that contained in green tea are epigallocatechin (EGC), epigallocatechin gallate (EGCG), epicatechin gallate (ECG), and gallate epicatechin (GEC). ${ }^{8-10}$

Components in plants can be taken by extraction methods. The choice of solvent must consider several factors including selectivity, ability to extract, toxicity, ease of evaporation and also prices. ${ }^{11}$ The extraction solution used was adjusted to the polarity of the desired compound. According to the principle of like dissolves like, a solvent will dissolve compounds that have the same level of polarity. Flavonoids are polyphenol compounds that are widely distributed in plants. Flavonoid divided into two groups, namely aglycon flavonoids and glycoside flavonoids. Aglycon flavonoid are flavonoids which do not bind sugar to their structure while glycosides flavonoid are flavonoids that bind sugar to their structure. The presence of sugar in the flavonoid structure causes the glycosides flavonoid become polar compounds while the aglycons flavonoid are less polar. Catechin 
in green tea leaves are the polar flavonoid compound. Polar solvents commonly used for extraction of flavonoids are methanol, acetone, ethanol, ethyl acetate, water and isopropanol. Therefore, this research was conducted to separate the flavonoids contained in green tea leaves from other compounds to obtain a fraction with high levels of flavonoids which have strong antioxidants activity and to see the effect of polarity solvent used. Green tea leaves are macerated using $96 \%$ ethanol. Fractination was performed by liquid-liquid partition method using a solvent of $\mathrm{n}$-hexane, ethyl acetate and water to obtain water fraction and ethyl acetate fraction. Ethanolic extract, water fraction and ethyl acetate fraction were measured for total flavonoid content and total phenolic content and then tested for antioxidant activity using DPPH method and ascorbic acid as standard. Substances that had the highest antioxidant activity will be measured for catechin levels.

\section{MATERIALS AND METHODS}

\section{Plant materials}

Green tea leaves (Camellia sinensis L.) obtained from Gunung Mas Plantation, Bogor, West Java, Indonesia and determined in Herbarium Bogoriense, Botanical Field, Biology Research Center-LIPI, Cibinong, West Java, Indonesia.

\section{Preparation of green tea leaves powder}

Green tea leaves were collected, sorted and then dried by oven at temperature $40^{\circ} \mathrm{C}-50^{\circ} \mathrm{C}$ for seven days. The green tea leaves powder are made by grinding the dried green tea leaves using a grinder. The green tea leaves powder is kept in a brown bottle tightly closed, protected from sunlight and humid air.

\section{Preparation of ethanolic extract of green tea leaves}

The green tea leaves powder was used 1000 grams. One part of green tea leaves powder was added 7 parts of $96 \%$ ethanol. The powder is soaked in $96 \%$ ethanol for one day and stirred every 6 hours. This process was repeated six times and maceration time for three days. All the macerates were collected and concentrated with a vacuum evaporator until the solvent evaporated perfectly or viscous ectract was obtained.

\section{Preparation of ethyl acetate and water fraction}

Fractionation of ethanolic extract was carried out by liquid-liquid extraction method (ECC). An amount of ethanolic extract was dissolved in $200 \mathrm{~mL}$ of distilled water and then put into a separating funnel and added n-hexane at an amount equal to the first solvent. Then, it was shaken with occasional air inside the funnel issued. The n-hexane fraction and water fractions were separated. Into the water fraction was added the same amount of ethyl acetate and shaken as above to obtain ethyl acetate fraction.

\section{Qualitative analysis of flavonoids}

Qualitative analysis was carried out for identification of flavonoids. Identification of the presence of flavonoids was carried out according to the procedures in WHO guidelines and Harborne. ${ }^{11,12}$

\section{Determination of total flavonoids content}

The flavonoids content was determined by aluminium trichloride colorimetric method using quercetin as reference compound. This method was modified from the procedure reported by Chang et al. ${ }^{13}$ Quercetin was used to make the calibration curve. One milliliter of quercetin was dissolved in $96 \%$ ethanol and then diluted to $2.0 ; 4.0 ; 6.0$, 8.0 and $10.0 \mu \mathrm{g} / \mathrm{mL}$. The diluted standard solutions were separately mixed with $3.0 \mathrm{~mL}$ of $96 \%$ ethanol, $0.2 \mathrm{~mL}$ of aluminum trichloride, $0.2 \mathrm{~mL}$ of $1 \mathrm{M}$ potassium acetate and $5.6 \mathrm{~mL}$ of distilled water. After incubation at room temperature for $30 \mathrm{~min}$, the absorbance of the reaction mixture was measured at $440 \mathrm{~nm}$ with a UV-Vis spectrophotometer. Similarly, $2.5 \mathrm{~mL}$ of ethanolic extracts, water fraction and ethyl acetate fraction $(100 \mu \mathrm{g} / \mathrm{mL})$ were reacted with aluminum trichloride for determination of flavonoid content as described above. The sample solution was carried out three replications.

\section{Determination of total phenolic content}

The phenolics content was determined by colorimetric method using gallic acid as reference compound. This method was modified from the procedure reported by Singleton et al. ${ }^{14}$ Gallic acid was used to make the calibration curve. Ten milligrams of gallic acid was dissolved in methanolic solution and then diluted to $0.5 ; 1.0 ; 5.0 ; 10.0$ dan 25.0 $\mu \mathrm{g} / \mathrm{mL}$. The diluted standard solutions were introduced into the test tubes, $0.4 \mathrm{~mL}$ of Folin-Ciocalteu's reagent and $4.0 \mathrm{~mL}$ of $7 \%$ sodium carbonate were added. The tubes were mixed with distilled water and allowed to stand for 2 hours. The absorbance of the reaction mixture was measured at $744.8 \mathrm{~nm}$ with a UV-Vis spectrophotometer. Similarly, $1.0 \mathrm{~mL}$ of ethanolic extracts, water fraction and ethyl acetate fraction were reacted as described above. The sample solution was carried out three replications.

\section{Determination of antioxidant activity}

Antioxidant activity was carried out based on the modification of standard DPPH method ${ }^{15,16}$ in which DPPH solution was prepared with a concentration of $0.4 \mathrm{mM}$. The antioxidant activity of green tea leaves was assessed in comparison to standard antioxidant ascorbic acid. Ascorbic acid as a comparison was made with a concentration of 1.0; 3.0; 5.0; 7.0 and $9.0 \mu \mathrm{g} / \mathrm{mL}$ using methanolic solution as a solvent. The ethanolic extract, water fraction and ethyl acetate fraction were made at a concentration of $1.0 ; 5.0 ; 10.0 ; 15.0$ and $20 \mu \mathrm{g} / \mathrm{mL}$ using methanolic solution as a solvent. Each test solution and reference mixed with $600 \mu \mathrm{L}$ of $0.4 \mathrm{mM}$ DPPH and methanol solution to $3.0 \mathrm{~mL}$ and homogenized. The test solution with several concentrations was incubated at $37^{\circ} \mathrm{C}$ in waterbath for 30 minutes. Then the mixture was measured at 517 $\mathrm{nm}$ with a UV-Vis spectrophotometer. From the absorbance obtained, percentage inhibition and regression curves were made, and the linear equation was applied to calculate the IC50.

Scavenging activity $(\%)=\left(\frac{A-B}{A}\right) \times 100$

where A is absorbance of control (DPPH solution without the sample), $\mathrm{B}$ is the absorbance of DPPH solution in the presence of the sample (test solution and ascorbic acid). The scavenging activity (\%) or \% inhibition was then plotted against log concentration and from the graph IC50 (Inhibition concentration 50) value was calculated by linear regression analysis.

\section{Determination of catechin}

Determination of cathecin was carried out in a test solution that has the best antioxidant activity. This study used High Performance Liquid Chromatography (HPLC) system. This method was modified from the procedure reported by Saito et al. ${ }^{17}$ COSMOSIL packed column $\mathrm{SC}_{18}$ MS-II $4.6 \mathrm{ID} \times 150 \mathrm{~mm}$ was used as column in this study. Photometric diode array (PDA) was used for both the operation of the detector and for data processing. Detection was carried out by measurement of UV absorbance at $278 \mathrm{~nm}$. The mobile phase was composed of water/ acetonitrile/methanol/o-phosphoric acid/ethyl acetate (77.5:18:2:0.5:12 $\mathrm{v} / \mathrm{v})$. The mobile phase flow rate started at $1.0 \mathrm{~mL} / \mathrm{min}$ and inject volume in this study was $10.0 \mu \mathrm{L}$.

Catechin used as standard for this determination. Catechin as a comparison was made with a concentration of $62.5 ; 125.0 ; 250.0$; 500.0 and $1000.0 \mu \mathrm{g} / \mathrm{mL}$ using methanolic solution as a solvent. Ten 
milligrams of samples dissolved in methanolic solution. Then 10.0 $\mu \mathrm{L}$ of catechin solution and sample solution was injected to HPLC system.

\section{RESULTS}

The collection of green tea leaves (Camellia sinensis L) was obtained from the Gunung Mas Plantation, Bogor, West Java, Indonesia. The macroscopic characteristics of green tea leaves can be seen in Figure 1. Green tea leaves are light green to dark green with an average length of no more than $5 \mathrm{~cm}$, short stalked, coriaceous, alternate, lanceolate and serrate margin. Green tea leaves's smell is aromatic and taste is little tight.

Green tea leaves was collected, sorted and dried so green tea leaves simplicia was obtained. The green tea leaves powder are made by grinding the dried green tea leaves using a grinder. The green tea leaves produced is green. The morphology of simplicia and green tea leaves powder can be seen in Figures 2A and 2B. Green tea leaves powder was macerated using $96 \%$ ethanol and concentrated using a vacuum evaporator to obtain a viscous ethanolic extract. The ethanolic extract produced was viscous concentrated brown extract, weighing 291.57 g (29.15\% yield) (Figure 2C). Furthermore, the ethanolic extract was fractionated by the liquid-liquid partition method using n-hexane, ethyl acetate and water solvents to obtain the n-hexane fraction, ethyl acetate fraction and water fraction. The yields of $\mathrm{n}$-hexane, ethyl acetate and water fractions were $44.43 \mathrm{~g}$ ( $4.44 \%$ yield), $83.77 \mathrm{~g}$ ( $8.38 \%$ yield) and $21.16 \mathrm{~g}(2.12 \%$ yields). consecutively.

Ethanolic extract, n-hexane fraction, ethyl acetate fraction and water fraction were carried out qualitative test of flavonoid. The results of the qualitative test of flavonoid showed that in ethanolic extract, ethyl acetate fraction and water fraction contained flavonoids. However, the $\mathrm{n}$-hexane fraction did not contain flavonoids. This result can be seen in Table 1.

From the results of qualitative tests of flavonoids, the $\mathrm{n}$-hexane fraction was not continued as a test material in subsequent studies because it did not contain flavonoids.

Ethanolic extract, ethyl acetate fraction and water fraction were measured for total flavonoids content using UV-Vis spectrophotometer.

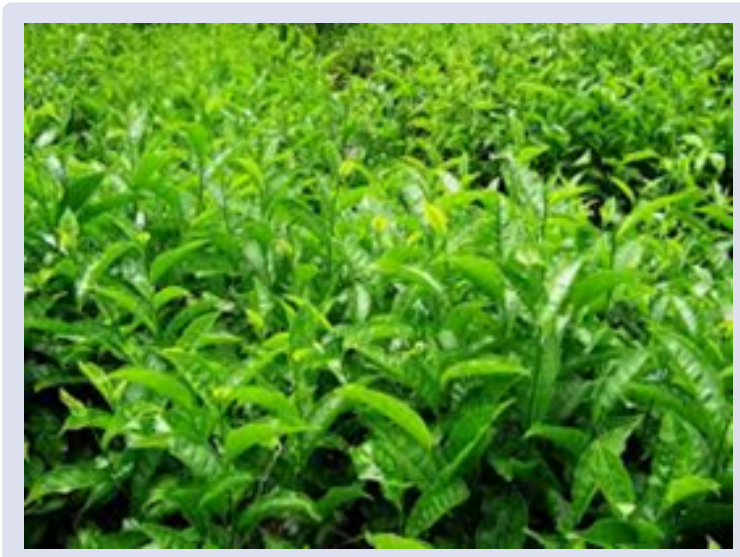

Figure 1: Field view of green tea (Camellia sinensis L.) plant.

Table 1: The result of qualitative test of flavonoids.

\begin{tabular}{lcccc}
\hline Compound & $\begin{array}{c}\text { Ethanolic } \\
\text { Extract }\end{array}$ & $\begin{array}{c}\text { n-Hexane } \\
\text { Fraction }\end{array}$ & $\begin{array}{c}\text { Ethyl } \\
\text { Acetate } \\
\text { Fraction }\end{array}$ & $\begin{array}{c}\text { Water } \\
\text { Fraction }\end{array}$ \\
\hline Flavonoids & + & - & + & + \\
\hline
\end{tabular}

Description: (+)means it contains flavonoids, (-) means it does not contain flavonoids.

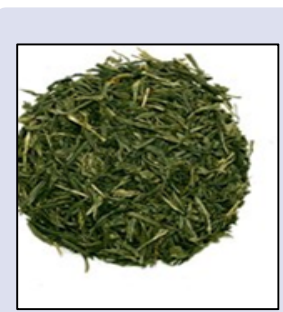

(A)

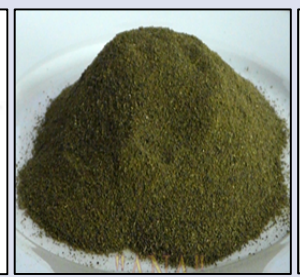

(B)

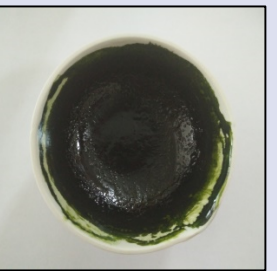

(C)
Figure 2: A. Simplicia of green tea leaves; B. Powder of green tea leaves; C. Ethanolic extract of green tea leaves.

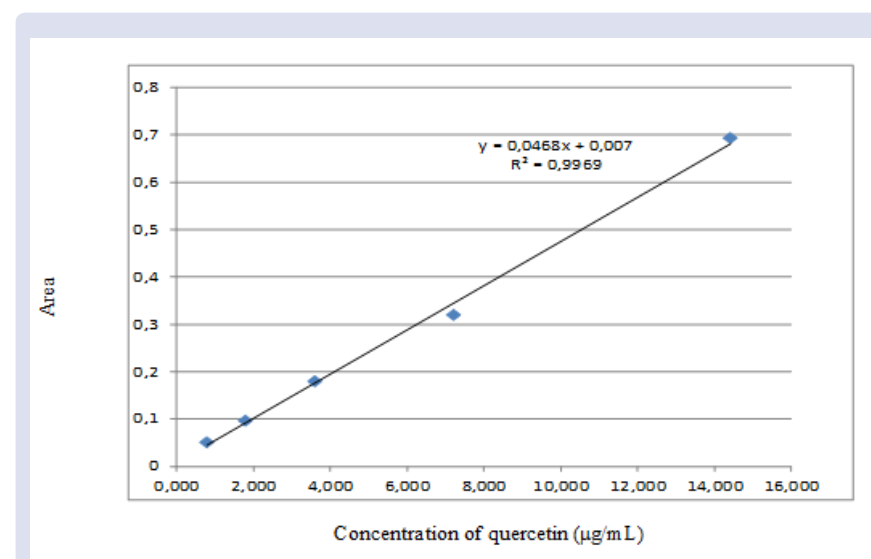

Figure 3: Calibraton curve of quercetin standard.

Determination of total flavonoids content using the colorimetric method which refers to the procedure of Chang et al. ${ }^{13}$ Quercetin was used as the standard. The regression equation obtained from the calibration curve against the standard quercetin is $y=0.0468 x+0.007$ with R2 of 0.9969 which indicates that the curve is linear (Figure 3).

From the regression equation, the total flavonoids content in ethanolic extract, ethyl acetate fraction and water fraction can be calculated. The results of total flavonoids content can be seen in Figure 4.

Based on the results, the three samples have been shown to contain flavonoids according to the qualitative tests previously conducted but the highest total flavonoid content were found in ethyl acetate fractions $(0.54 \%)$ and the lowest total flavonoids content were found in the water fraction $(0.14 \%)$.

In this study also measured total phenolic content. Total phenolic content was determined using the Folin-Ciocalteu method using UVVis spectrophotometry. Gallic acid was used as a standard in this test and produces a linear regression equation, $y=0.0216 x-0.0011$ with $R 2$ of 0.9941 (Figure 5).

The total phenolic content of ethanol extract, ethyl acetate fraction and water fraction can be calculated using the regression equation obtained. The results of total phenol levels can be seen in Figure 6 .

From the results above, it can be seen that the largest total phenolic content of green tea leaves is in the ethyl acetate fraction $(42.34 \%)$, then followed by ethanolic extract $(31.16 \%)$ and the lowest is in the water fraction $(23.78 \%)$. These results are linear with the results of total flavonoids content.

Based on the three tests that have been carried out, it is proven that ethanolic extract, ethyl acetate fraction and water fraction contain flavonoids and phenolic compounds which acts as antioxidant compounds, although with different levels. So the three samples were continued to antioxidant activity test using DPPH method. In this test, ascorbic acid was used as a standard. The results obtained from this 


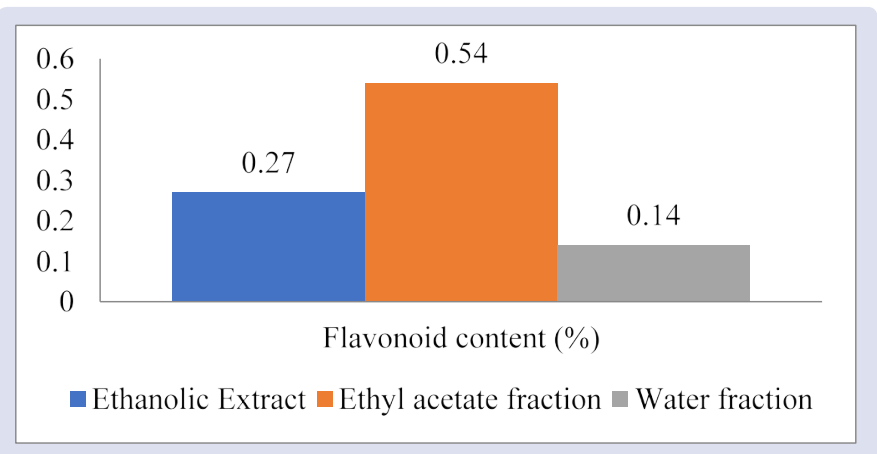

Figure 4: The result of total flavonoids content.

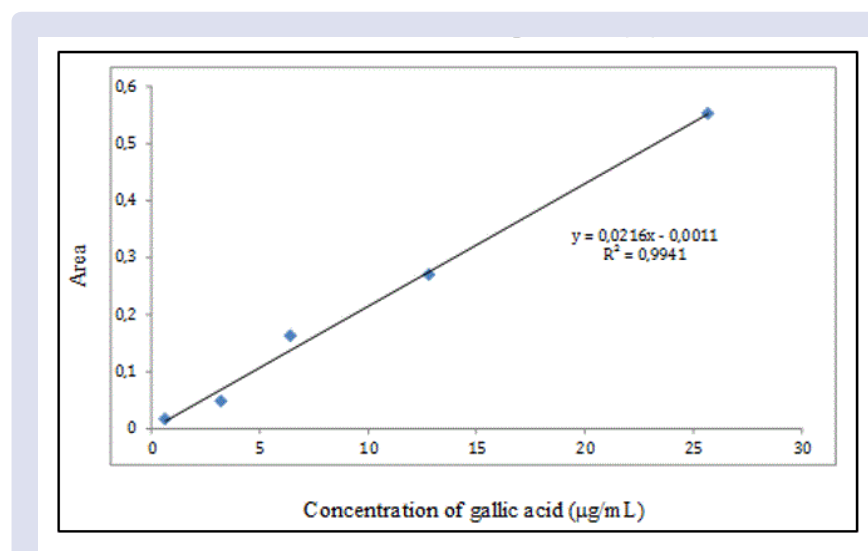

Figure 5: Calibration curve of gallic acid standard.

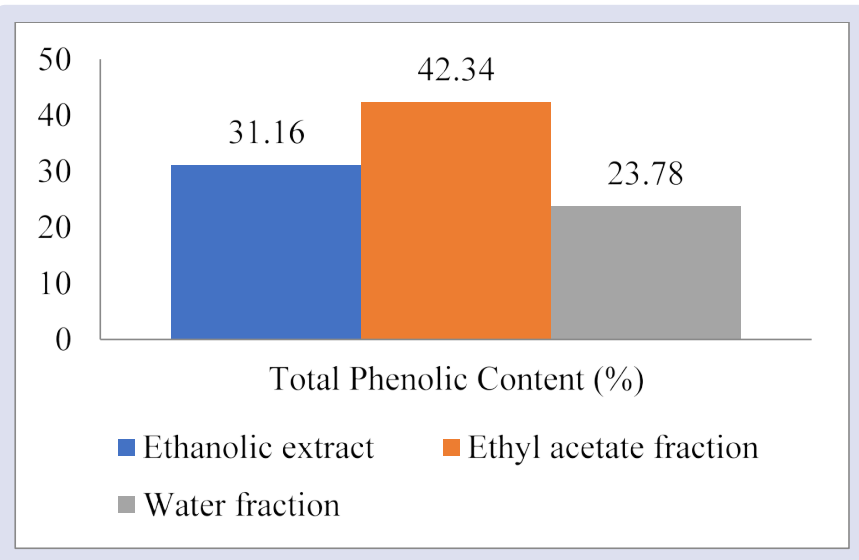

Figure 6: The result of total phenolic content.

study are $\mathrm{IC}_{50}$ values (Inhibition Concetration 50). $\mathrm{IC}_{50}$ value states the antioxidant concentration $(\mu \mathrm{g} / \mathrm{mL})$ which can inhibit $50 \%$ of free radicals. The smaller the $\mathrm{IC}_{50}$ value means the antioxidant activity become stronger. The $\mathrm{IC}_{50}$ value results from the antioxidant activity test can be seen in Figure 7.

Based on Figure 7, ethyl acetate fraction has the smallest $\mathrm{IC}_{50}$ value of $3.926 \mu \mathrm{g} / \mathrm{mL}$ which means that ethyl acetate fraction has strong antioxidant activity. While the largest $\mathrm{IC}_{50}$ value is in ethanolic extraxt $(9,017 \mu \mathrm{g} / \mathrm{mL})$. From the above results it is also seen that the $\mathrm{IC}_{50}$ ethyl acetate fraction is smaller than the positive control (ascorbic acid). This results indicate that antioxidant activity of ethyl acetate fraction is better than ascorbic acid.

Ethyl acetate fraction has proven have the best antioxidant activity so in this study ethyl acetate fraction was measured for catechin levels. Catechins are the main polyphenol content in green tea leaves which act as antioxidants. Catechins was used as a standard in this test and produce a linear regression equation that is $\mathrm{y}=7453.9 \mathrm{x}-154172$ with R2 of 0.9958 (Figure 8).

The regression equation is used to calculate the level of catechin in ethyl acetate fractions. Ethyl acetate fraction contains catechin of $309.77 \mu \mathrm{g} /$ $\mathrm{mL}$. The results of the chromatogram and the level of catechin in ethyl acetate fraction can be seen in Figure 9 and Table 2.

\section{DISCUSSION}

Green tea leaves can act as antioxidants due to its polyphenol compounds. Polyphenols are a group of plant-based chemicals that have at least one phenol group. Flavonoids are included in a large group of polyphenols contained in green tea leaves. Flavonoids are also known act as antioxidants. Flavonoids are divided into several groups such as flavones, flavonols, isoflavones, catechins, flavanones, leukoantocyanins, aurons, chalcons and dihydroflavonols. Catechins are polyphenol or flavonoids compounds contained in green tea in high concentration around $45-90 \% .^{18,19}$

Ethanolic extract, ethyl acetate fraction and water fraction proved to contain flavonoids. While the n-hexane fraction does not contain flavonoids. This is because the ability of the solvent to dissolve flavonoids depending on the level of polarity of the solvent and the extracted
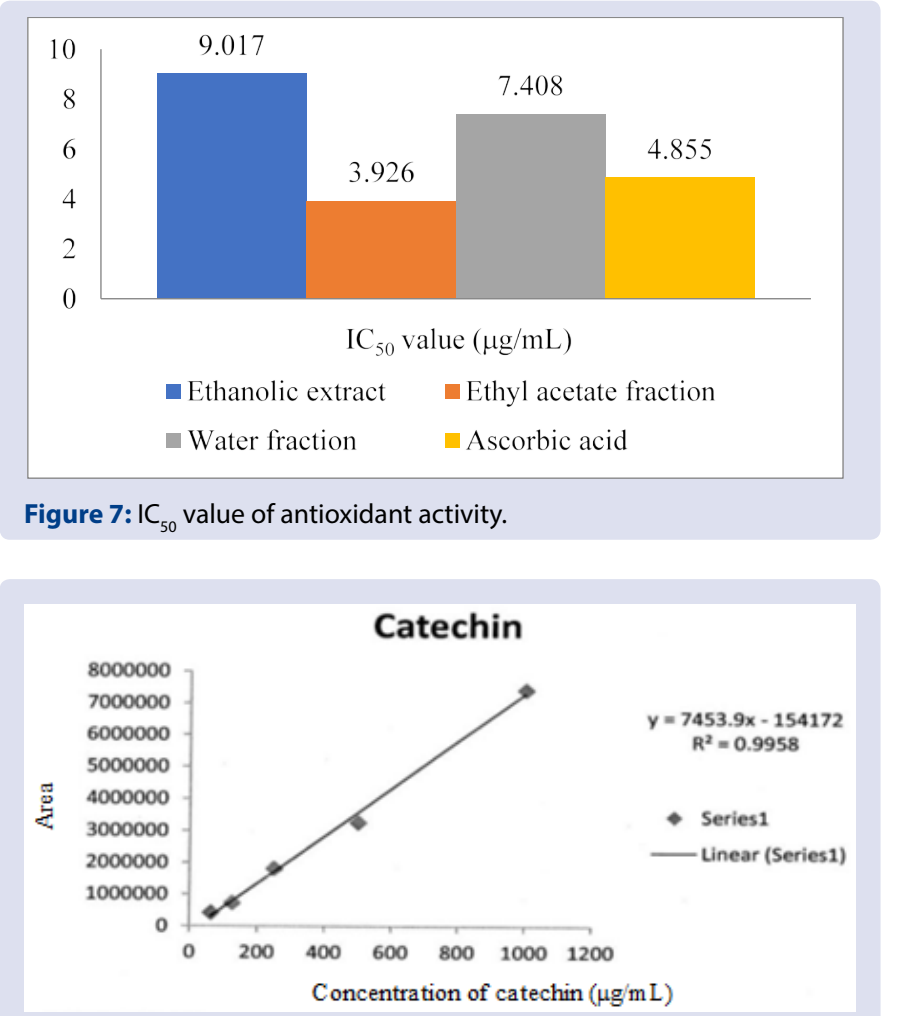

Figure 8: Calibration curve of catechin standard.

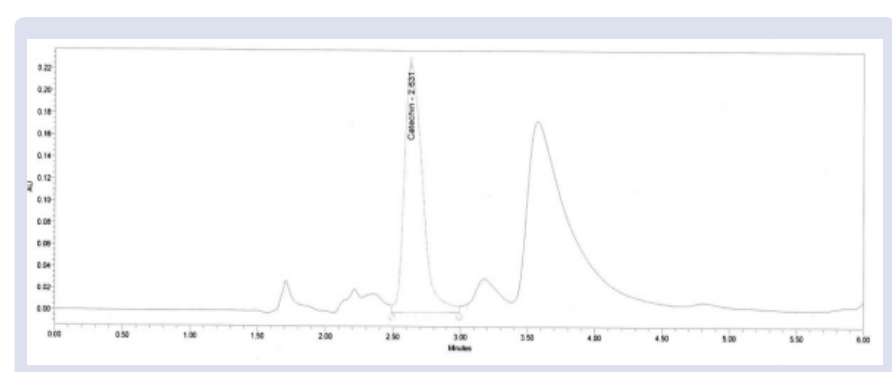

Figure 9: Chromatogram of ethyl acetate fraction. 
Table 2: The level of catechin.

\begin{tabular}{|c|c|c|c|c|c|c|c|c|}
\hline Sample & Concentration & RT & Area & $\begin{array}{c}\text { Average of } \\
\text { RT }\end{array}$ & $\begin{array}{c}\text { Average of } \\
\text { Area }\end{array}$ & SD & RSD & $\begin{array}{c}\text { Content }(\mu \mathrm{g} / \\
\mathrm{mL})\end{array}$ \\
\hline \multirow{3}{*}{$\begin{array}{l}\text { Ethyl acetate } \\
\text { fraction }\end{array}$} & \multirow{3}{*}{$1 \mathrm{mg} / \mathrm{mL}$} & 2.631 & 2131245 & \multirow{3}{*}{2.631} & \multirow{3}{*}{2154797.33} & \multirow{3}{*}{33870.68} & \multirow{3}{*}{1.57} & \multirow{3}{*}{309.77} \\
\hline & & 2.630 & 2139533 & & & & & \\
\hline & & 2.631 & 2193614 & & & & & \\
\hline
\end{tabular}

compound. ${ }^{11}$ According to Harborne ${ }^{11}$ flavonoid compounds have different polarity depending on the number and position of the hydroxyl group. In general, flavonoids are divided into two major groups, namely aglycones flavonoid and glycosides flavonoid. Aglycones flavonoid are flavonoids which do not bind sugar to their structure while glycosides flavonoid are flavonoids that bind sugar to their structure. The presence of sugar in the flavonoid structure causes the glycosides flavonoid become polar compounds while the flavonoid aglycons are less polar. In the n-hexane filtrate, flavonoids content is undetectable because $\mathrm{n}$-hexane is a non polar solvent. This is in line with several previous studies which state that aquadest is effective for extracting glycoside compounds, amino acids, and sugar. ${ }^{20}$ Ethyl acetate is effective for extracting alkaloids, aglycons, and glycoside compounds, ${ }^{20}$ sterols, terpenoids, and flavonoids. ${ }^{21}$ Hexanes can solve non-polar compounds, such as lignin, wax, lipid, sterol, and terpenoids. ${ }^{21}$

Effectivity of ethyl acetate fraction was supported by total flavonoids and total phenolic content. Total flavonoid in ethyl acetate fraction also showed the biggest concentration compared with the others (Figure 4). Ethyl acetate filtrate has the biggest flavonoid content because the polarity of flavonoids is polar and less polar so that it is more easily extracted to semipolar solvents such as ethyl acetate. These results also correlate with the result of total phenolic contain. The ethyl acetate fraction contains the highest total phenolic. Ethanolic extract has higher total flavonoid content and total phenolic content than water fraction because the ethanolic extract has not been separated so that polar and semipolar compounds are still contained in ethanolic extract. Unlike the fraction of water that has undergone fractionation so the content contained in water fractions is polar compounds.

Antioxidant activity of ethanolic extract, ethyl acetate fraction and water fraction was carried out. The method used in antioxidant activity test is the DPPH radical uptake method because it is a simple, easy method, and uses a small amount of sample. ${ }^{22}$ In addition, this method does not require a substrate because free radicals are available directly to replace the substrate. DPPH molecule is a free radical molecule in the presence of electrons delocalization around the molecule. The presence of antioxidant activity from the sample resulted in discoloration of the DPPH solution in methanol. ${ }^{23}$ This method uses $\mathrm{IC}_{50}$ as a parameter to determine the concentration of antioxidant compounds that can inhibit $50 \%$ of free radicals. According to Jun et al., as well as other text books, ${ }^{24,25}$ antioxidant activity is categorized as a very powerful when IC50 $<50 \mu \mathrm{g} / \mathrm{mL}$, strong if IC50 values of $50-100 \mu \mathrm{g} / \mathrm{mL}$, moderate at $101-250 \mu \mathrm{g} / \mathrm{mL}$, and weak when IC50 $250-500 \mu \mathrm{g} / \mathrm{mL}$, and classified as inactive when the IC50 $>500 \mu \mathrm{g} / \mathrm{mL}$. The value of total flavonoid content and total phenolic content can be correlated with the total antioxidant activity which wasrepresented by the $\mathrm{IC}_{50}$ of DPPH. Ethyl acetate filtrate has the strongest antioxidant activity compared to ethanolic extract, water filtrate and ascorbic acid as positive control. But when viewed from the $\mathrm{IC}_{50}$ results, ethanolic extract, ethyl acetate filtrate and water filtrate are categorized as a very powerful antioxidant activity because the $\mathrm{IC}_{50}$ value is less than $50 \mu \mathrm{g} / \mathrm{mL}$. The antioxidant capacity of flavonoid and phenolic compounds is essentially due to the presence of high activity as hydrogen or electron donor where a hydrogen atom from an aromatic hydroxyl $(\mathrm{OH})$ group can be donated to a free radical. ${ }^{26,27}$ The ethyl acetate filtrate which has the strongest antioxidant activity was measured for its catechin content and the results showed that the catechin content in ethyl acetate filtrate was $309.77 \mu \mathrm{g} / \mathrm{mL}$.

\section{CONCLUSION}

The ethyl acetate fraction contains the largest flavonoid compounds compared to other extract so it can be used as a souce of antioxidant bioactive substances in green tea leaves.

\section{CONFLICT OF INTEREST}

The authors have no conflict of interest to declare.

\section{REFERENCES}

1. Birben E, Sahiner UM, Sackesen C, Erzurum S, Kalayci O. Oxidative stress and antioxidant defense. World Allergy Organ J. 2012;5(1):9-19.

2. Pandhair $V$, Sekhon BS. Reactive oxygen species and antioxidants in plants: An overview. Journal of Plant Biochemistry and Biotechnology. 2006;15(2):71-8.

3. Poumorad F, Hosseinimehr SJ, Shahabimajd N. Antioxidant activity phenol and flavonoid contents of some selected Iranian medical plants. Afr J Biotechnol 2006;5(11):1142-5.

4. Dalimartha S. Atlas Indonesian medicinal plants. $1^{\text {st }}$ Ed. Jakarta: Trubus Agriwidya, p.146-149;1999.

5. Kikuzaki H, Hisamoto M, Hirose K, Akiyama K, Taniguchi H. Antioxidants properties of ferulic acid and its related compound. J Agric Food Chem. 2002;50(7):2161-8

6. Forester SC, Joshua D. Antioxidant effects of green tea. Mol Nutr Food Res. 2011;55(6):844-54

7. Sharangi $A B$. Medicinal and therapeutic potentialities of tea (Camellia sinensis L.)-A review. Food Research International. 2009;42(5-6):529-35.

8. Alcazar. Differentiation of green, white, black, Oolong, and Pu-erh teas according to their free amino acids content. Journal of Agricultural and Food Chemistry. 2007;55(15):5960-5.

9. Hilal $Y$, Engelhardt U. Characterization of white tea-comparison to green and black tea. J Vergbr Lebensm. 2007;2(4):414-21.

10. Unachukwu UJ. White and green teas (Camellia sinensis var.sinensis): variation in phenolic, methylxanthine, and antioxidant profiles. Journal of Food Science. 2010;75(6):541-8

11. Harborne JB. Methods of phytochemistry. Kosasih P, Soediro I (Eds.). Bandung Publisher ITB; 1987

12. World Health Organization. Quality control methods for medicinal plant materials. Geneva;1998.

13. Chang CC, Yang MH, Wen HM, Chern JC. Estimation of tota flavonoid content in propolis by two complementary colorimetric methods. $J$ Food Drug Ana. 2002;10(3):178-82.

14. Singleton VL, Orthofer R, Lamuela-Raventós RM. Analysis of total phenols and other oxidation substrates and antioxidants by means of folin-ciocalteu reagent. Methods in Enzymology. 1999;299:152-178.

15. Banker GS. Modern pharmaceutics drugs and the pharmaceutiucal science. $7^{\text {th }}$ Ed. New York: Marcel Dekker Inc, p.355;1997.

16. Braca AT, Nunziatina DB, Lorenzo D, Pizza C, Politi M, Morelli I. Antioxidant principles from bauhinia tarapotensis. J Nat Prod. 2001;64(7):892-5.

17. Saito S, Welzel A, Suyenaga SE, Francie B. A method for fast determination of epigallocatechin gallate (EGCG), epicatechin (EC), catechin (C) and caffeine (CAF) in green tea using HPLC. Ciencia tecnol aliment campinas. 2006;26(2):394-400

18. Kodama DH, Any Elisa de Souza SG, Franco ML, Maria IG. Flavonoids, tota phenolics and antioxidant capacity: comparison between commercial green tea preparations. J of Ciencia e Tecnologia de Alimentos. 2010;30(4):1077-82.

19. Vinson JA. Black and green tea and heart disease: A review. Biofactors 2000;13(1-4):127-32.

20. Houghton PJ, Raman A. Laboratory handbook for the fractionation of natural extracts. New York:Chapman and Hall;1998.

21. Cowan MM. Plant product as antimicrobial agents. Journal of Microbiology Reviews. 1999;12(4):564-82.

22. Hanani E, Munim A, Sekarini R. Identifikasi senyawa antioksidan dalam spons callyspongia sp dari kepulauan seribu. Majalah Ilmu Kefarmasian. 2005;2(3):12733. 
23. Permana DN, Lajis H, Abas F, Ghafar Othman A, Ahmad R, Kitajama M, et al. Antioksidative constituents of hedotis diffusa wild. Natural Product Sciences. 2003;9(1):7-9.

24. Jun M, Fu HY, Hong J, Wan X, Yang CS, Ho CT. Comparison of antioxidant activities of isoflavones from kudzu root (Pueraria labata Ohwi). J Food Sci Technol. 2003;68(6):2117-22.
25. Shahidi F. Natural antioxidant: Chemistry, health effects, and applications. USA:AOCS Press;1997.

26. Leopoldini M, Russo N, Toscano M. The molecular basis of working mechanism of natural polyphenolic antioxidants. Food Chemistry. 2011;125(2):288-306

27. Nakiboglu M, Urek RO, Kayali HA, Tarhan L. Antioxidant capacities of endemic Sideritis sipylea and Origanum sipyleum from Turkey. Food Chemistry. 2007;104(2):630-35.

\section{GRAPHICAL ABSTRACT}

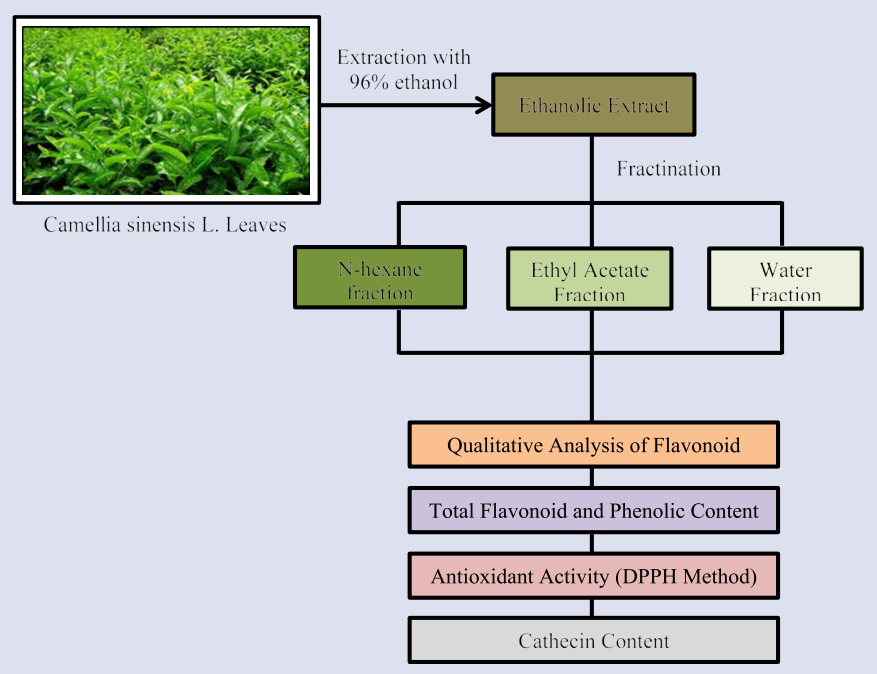

\section{SUMMARY}

Camellia sinensis L. leaves were extracted with $96 \%$ ethanol to obtain ethanolic extract. Ethanolic extract were freactinated with n-hexane, ethyl acetate and water to obtain n-hexane fraction, ethyl acetate fraction and water fraction. Ethanolic extract, ethyl acetate fraction and water fraction were contained flavonoid. The highest total flavonoid content and total phenolic content resulted from ethyl acetate fraction. Ethyl acetate fraction also has strongest antioxidant activity than the others with $I C_{50}$ value of $3.926 \mu \mathrm{g} / \mathrm{mL}$. From this study, it can be concluded that ethyl acetate fraction can be used as a souce of antioxidant bioactive substances in green tea leaves.

\section{ABOUT AUTHORS}

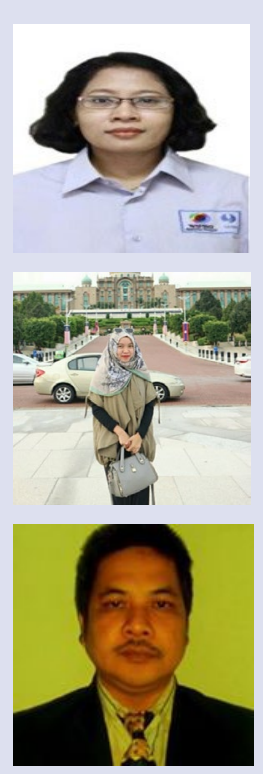

Karmika Indarti: Student of magister program in Faculty of Pharmacy, Pancasila University.

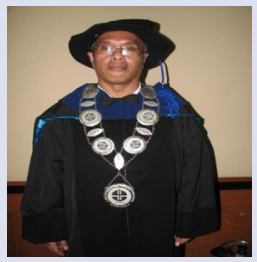

Elsa Fitria Apriani: Lecturer and Researcher in Department of Pharmacy, Faculty of Mathematics and Natural Sciences, Sriwijaya University.

Agung Eru Wibowo: Researcher in Center for Pharmaceutical and Medical Technology, Agency for the Assessmenet and Application of Technology (BPPT) Puspiptek Serpong.

Partomuan Simanjuntak: Lecturer and Researcher in Faculty of Pharmacy, Pancasila University.

Cite this article: Indarti $K$, Apriani EF, Wibowo AE, Simanjuntak P. Antioxidant Activity of Ethanolic Extract and Various Fractions from Green Tea (Camellia sinensis L.) Leaves. Pharmacog J. 2019;11(4):771-6. 